\title{
Granting learners an authentic voice in the mathematics classroom for the benefit of both the teacher and the learner
}

\author{
Authors: \\ Herbert B. Khuzwayo \\ Sarah Bansilal ${ }^{2}$ \\ Affiliations: \\ ${ }^{1}$ Department of \\ Mathematics, Science and \\ Technology Education, \\ University of Zululand \\ South Africa
}

${ }^{2}$ Department of Mathematics Education, School of

Education, University of

KwaZulu-Natal, South Africa

\section{Correspondence to:}

Sarah Bansilal

Email:

bansilals@ukzn.ac.za

\section{Postal address:}

8 Zeeman Place, Malvern

4093, South Africa

Dates:

Received: 14 Mar. 2012

Accepted: 04 Oct. 2012

Published: 14 Dec. 2012

How to cite this article: Khuzwayo, H.B., \& Bansilal, S. (2012). Granting learners an authentic voice in the mathematics classroom for the benefit of both the teacher and the learner. Pythagoras, 33(2), Art. \#163, 7 pages. http://dx.doi. org/10.4102/pythagoras. v33i2.163
C) 2012. The Authors. Licensee: AOSIS OpenJournals. This work is licensed under the Creative Commons Attribution License.
An important aspect of democratic education is the value it places on providing spaces for disagreement and argument as opportunities for learning. This is unlike an 'occupation of the minds' philosophy, which denies people the right to see alternatives. In this article we explore one aspect of this area of democratic education: the issue of providing opportunities for learners' voices. We acknowledge the importance of this, even if the voices are dissenting; such dissent is important for teachers to learn more about the learners. We subsequently look at the kind of listening that a teacher can do in order to learn, and consider some cases from literature about teachers who struggle to listen and what happens when they learn to listen to their learners. Finally, we argue that a perspective aligned with preparing learners to contribute to a democratic society advises a rethink of the construct of mathematical knowledge for teaching. By learning how to listen in a respectful manner and as part of a negotiation and co-evolution of shared understanding, teachers can deepen and shift their understanding of mathematics, their understanding of learners and their understanding of their own learning.

\section{Introduction}

On the critical nature of mathematics, Skovsmose (2004) states that 'mathematics education could mean empowerment, but also suppression. It could mean inclusion but also exclusion and discrimination' (p. 2). Although he does not endorse claims about the existence of intrinsic connections between mathematics and democratic values, or claims that mathematics education can serve anti-democratic interests, Skovsmose does suggest that 'mathematics must be reflected on and criticized in its variety of forms of action' (p. 2). In this article, in addition to looking at the teachers' role in empowering learners by creating spaces for their voices, we reflect on how this process can also empower teachers by providing opportunities to deepen their own mathematical knowledge for teaching.

Khuzwayo (1998) argues that a dominant feature in mathematics education in South Africa during the apartheid years was the attention paid to the 'occupation of our minds' (p. 219). He states that redress in mathematics education in South Africa will require serious commitment to ending this occupation. An occupation perspective denies people the opportunity to see alternatives. This is played out in the process of the development of a curriculum, the style of textbooks, the notion of success and the kind of teaching that is encouraged in classrooms. He states that 'we have been blinded so that we are unable to see the alternatives in both our teaching and learning of mathematics' (Khuzwayo, 1998, p. 221). Another characteristic of the occupation of the minds philosophy is its focus on obedience to authority and passiveness; it discourages curiosity and independence. Fasheh (1996) emphasises that 'ending the occupation of our minds is a personal task, its continuation depends solely on our acceptance of it. So is its termination' (pp. 25-26).

In this article, we look at one of the implications of such a commitment. We argue that a concern with development and democracy in mathematics education requires an interrogation of the kind of classroom that is needed to initiate a disruption of the occupation. Of course such a disruption will require attention to many facets and in this article we focus on one issue: how teachers benefit when they grant learners a real voice in the classroom.

In preparing learners to participate in and contribute to a democratic society, we will need to give them opportunities to experience such processes. It is increasingly important, particularly in South Africa, for people to realise that democracy involves responsibility. In order to avoid a situation where 'citizens and public officials can use democratic principles to destroy democracy' (Guttmann, 1987, p. 4), citizens need to see that democracy grants all people the right to voice their views. This aspect, where contestation is not only allowed but actively sought, is a valuable component of democracy. As Guttman argues: 
The most distinctive feature of a democratic theory of education is that it makes a democratic virtue of our inevitable disagreement over educational problems in a way much more likely to increase our understanding of education and of each other ... (p. 11)

This supports the notion that contestation is an important part of democratic processes and must be valued and supported, not reduced or suppressed. Thus a democratic theory of education presupposes a classroom where argument and disagreement are actively encouraged. Particularly in mathematics, contestation offers opportunities to increase our understanding of the subject, our understanding of learners and our understanding of teachers.

In a traditional mathematics context, however, a classroom is seen as the domain of the teacher: they set the agenda for the content, the opportunities for mediation of the content and the actual practices of mediation. How does this picture change when learners are granted a voice in the classroom - not a superficial voice, but an authentic voice that can influence what happens, why it happens and how it happens in the classroom?

One implication of creating space for learners' voices in a mathematics classroom is that as well as contributing to the learners' experiences of democracy and their own learning, this process also contributes to the teacher's mathematical knowledge for teaching. Current conceptions of the notion of mathematical knowledge for teaching (Ball, Hill \& Rowan, 2005) suggest that interactions with learners contribute to developing one component of a teacher's mathematical knowledge for teaching (knowledge oflearners and content). This limits the critical role learners can play in the development of all domains of mathematical knowledge for teaching. It also undermines the importance of acknowledging and listening to multiple potential meanings of voice from various democratic classroom settings (where the voice of the learner is considered to be important). This appears to be in contrast to issues raised by studies such as the Learner's Perspective Study (see Clarke, 2002). The findings of that study raised awareness of the role of learners as a legitimate voice to take into consideration when thinking about teachers' knowledge. By taking seriously the learners' voices we can enrich our attempts to develop a notion of mathematical knowledge for teaching by focusing on interacting with, observing and reflecting on the activity of the learners.

Mathematical knowledge for teaching has received much attention in recent times (Adler \& Davis, 2006; Adler, Pournara, Taylor, Thorne \& Moletsane, 2009; Ball \& Bass, 2000; Ball, Thames \& Phelps, 2008; Ball et al., 2005; Perressini, Borko, Romagnano, Knuth \& Willis, 2004). Ball et al. (2005) define four domains of mathematical knowledge for teaching: common content knowledge (mathematical knowledge of the school curriculum), specialised content knowledge (mathematical knowledge teachers make use of in teaching), knowledge of students and content (knowledge that combines knowledge of content and learners - in this domain, teachers need to be able to anticipate learner errors and common misconceptions, interpret learners' incomplete thinking and predict what learners are likely to do with specific tasks and what they will find interesting or challenging), and knowledge of teaching and content (knowledge about instructional sequencing of particular content, and about salient examples for highlighting mathematical issues). In these definitions the role of the learners in contributing to the development of the knowledge is relegated to the sidelines, just in terms of predicting what they would do in a particular situation. Let us look at the following statement more closely:

[Mathematical knowledge for teaching] allow[s] teachers to assess their students' work, recognizing both the sources of student errors and their understanding of mathematics being taught. They also can appreciate and nurture the creative suggestions of talented students. (Conference Board of the Mathematical Sciences, 2001, p. 3)

This statement suggests that teachers can only 'appreciate' and listen to some good suggestions of 'talented' students. It backgrounds the fact that interactions with learners can deepen teachers' knowledge in the different domains.

In this article we first consider the issue of providing opportunities for learners' voices. We then acknowledge that, even if the voices are dissenting, such dissent is important for teachers to learn more about the learners. We subsequently look at the kind of listening that a teacher can do in order to learn more, and consider some cases from literature about teachers who struggle to listen and what happens when they learn to listen to their learners. Finally, we argue that a potential benefit of preparing learners to contribute to a democratic society is the enhancement of the teacher's mathematical knowledge for teaching.

\section{Discussion}

\section{Providing opportunities for learners' voices, even if they are dissenting}

How do we create authentic opportunities for learners' voices, so that we learn about the learners, what they value and what they want? Vithal (1999) has shown that project work can be used as a site for learners to play a meaningful role in their own learning. She comments that:

during project work, as democracy comes to have a place in a mathematics classroom, authority gets rearranged, and in turn, the kinds of authority influences the forms of democratic life possible within a classroom or school. (p. 29)

In Vithal's (1999) study about project work in a primary mathematics classroom, it was found that the concerns driving the learners were different from those of the teacher:

While the teacher wanted to raise more general societal issues of differences and inequalities between pupils' background such as the parents' different incomes, ... the pupils focused on the specific issue of their school fees and their needs and concerns at school. (p. 29)

Although these differing drives may be a potential source of conflict, such situations present opportunities for teachers to learn more about the concerns that drive the learners. 
It is understandable that a learner and a teacher do not share the same perspective on classroom issues, but it may be surprising to hear learners voice their displeasure about certain practices, such as in assessment. Many teachers are burdened by large teaching and marking loads, and consequently may sometimes feel that they are doing their learners a favour when they mark assessments and return them timeously, expecting the learners to appreciate the effort it took to get the marking done in time. However, in a study by Bansilal, James and Naidoo (2010), Grade 9 learners expressed strong views about what they expected from their teachers in terms of responses to learners' work. They expected the teacher to provide meaningful feedback to their work, to diagnose their errors and to show them how they could close the gap. They expected the teacher to provide feedback that would improve their understanding. Clearly, learners have their own opinions about the teacher's responsibilities towards the learners' understanding. These findings confirm that teachers could enhance their mathematical knowledge for teaching by addressing learners' expectations.

Common advice to novice teachers is that they should walk around the classroom and offer advice to learners whilst learners work on their pre-assigned tasks. There is an assumption that all learners welcome feedback from their teachers. However, this may be a simplistic assumption by teachers and teacher educators. Naidoo's (2007) study identified a learner who preferred to 'call a teacher ... when you are stuck ... it's better ... instead of the teacher coming and bothering you all the time' (p. 72). The learner wrote in her journal that she hated it when she was in the middle of something and the teacher wanted to mark her work. She felt that the teacher's unsolicited feedback interrupted her concentration. Her remarks convey the sentiment that the teacher's presence was not always welcome when she was trying to work on her own. This is contrary to what teachers commonly believe about their offering of comments to learners - that it is always helpful and welcome. Acknowledging such unexpected reactions can help teachers to develop a more nuanced understanding of their learners' needs.

\section{Building, not breaking}

The intention of the teacher when listening to learners should be to build and not break a learner's confidence. The study by Bansilal et al. (2010) revealed that learners did not welcome derogatory comments about their abilities from their teachers, since they viewed these as personal. The study highlighted the role that the teacher plays in building or breaking a learner's self-confidence. It was found that shy learners were not confident enough to approach the teacher because, in their experience, there was a chance of their being insulted by the teacher. One learner said that she did not want to hear the words 'You are so stupid'. The learners felt belittled and lost their confidence when faced with teachers' negative comments. On a similar note, Moodley's (2008) study on South African learners' self-efficacy beliefs about mathematics reported that most learners (from her sample of
32 Grade 11 mathematics learners) felt that their mathematics teachers displayed a negative attitude towards them. Ninetyone per cent of her sample indicated that the teacher ignored them when they asked questions and 93\% indicated that the teacher made them feel silly when they asked questions in the mathematics classroom. Some of the learners' comments were: 'He tries to be funny but he doesn't know that he actually embarrasses and hurts people'; 'You know you afraid to ask questions. Maybe the teacher will make you feel stupid' and 'I hate being looked down upon' (pp. 57-59). These comments support the fact that when teachers make negative comments to learners, the learners are embarrassed and feel belittled. These unpleasant experiences discourage the learners from seeking help from their teachers.

Similarly, Young (2000) explains that the 'most powerful and potentially dangerous dimensions of students' feelings about feedback is the extent it impacts on themselves as people' (p. 414). In his study, derogatory verbal comments were experienced as being 'absolutely annihilating' for the learner in the learning experience.

\section{Learning to listen, listening to learn}

The studies cited above highlight the fact that learners have their own expectations of the teacher, which may be different from what the teacher assumes. Granting a learner a voice presupposes a willingness on the part of a teacher to listen. Effective teaching by listening depends on learners trusting, respecting and valuing the teacher. Maoto and Wallace (2006) suggest that to 'be alert to learners' learning requires a teacher who listens to learners' thinking rather than simply listens for the right answer' (p. 67). Maoto and Wallace detailed the hesitant progression of Gerty, a teacher from the Limpopo province in South Africa, in moving from always wanting to tell, to learning how to listen. As Gerty struggled to develop an awareness of her learners' understanding by examining ideas underlying their confusion, Gerty developed a deeper understanding of the learners' understanding of factorisation and other concepts. Maoto and Wallace provide an insightful interrogation of Gerty's interactions with one learner who did not use the equal sign appropriately, but wrote (p. 63):

$$
\begin{array}{lll}
3 a+6=3 & \text { and } & 6 a^{2} b^{2}-3 a^{2} b^{2}=3 a^{2} b^{2} \\
3(a+2)=1 & & 3 a^{2} b^{2}(2-1)=1
\end{array}
$$

Gerty, by listening to the learner, was able to separate his misuse of theequalsignnotation, and hissubsequenterroneous representation of factorisation, from his understanding of the process of factorisation. The learner's response reveals that he understands the three demands inherent in the process of factorisation of expressions (identifying a common factor to the different terms, extracting the factor and identifying the remaining factor of each term). However, the learner is unable to use the mathematical notations appropriately to represent these steps. By listening to the learner about his unorthodox ways of representing the factorisation process, 
Gerty enhanced her own specialised as well as her common content knowledge (Ball et al., 2005) in the area of factorisation and use of algebraic notation.

Gerty sought ways to design or adapt activities to meet her learners' needs by scrutinising textbooks, which further deepened her understanding in the domains mentioned. She used the learners' misconceptions to guide her remediation, which led her to examine mathematical ideas more closely, further enhancing her knowledge. Thus her engagement with her learners' understandings and struggles prompted her to refine her goals and extend her own understanding of what it means to teach for her learners' understanding. Maoto and Wallace (2006) note that learning to listen is a key aspect of teaching for understanding and they emphasise that it is necessary to spot the appropriate moments to tell, to know when to clear up a controversy, or to decide when it is good to probe.

Learning to listen can be seen as a catalyst for teacher learning, but what kinds of listening must a teacher engage in? Davis (1997) distinguishes between three types of listening:

- evaluative (listening for and checking)

- interpretive (listening to and recasting)

- hermeneutic (listening between the words and actions).

Listening for a predetermined answer and checking that what is said is what is expected means that the listener may misunderstand or fail to appreciate what is being expressed. It is listening that involves having a 'correct' answer in mind. In this situation, the listener is not really interested in what the other person is saying, beyond its match (or mismatch) to the expected answer. It also reinforces a culture of test and check for learners.

Listening to and recasting in their own terms (interpretive listening) can be valuable for a teacher. Listening to is characterised by deliberative attending, and suggests trying to understand the sense that the learner is making of the mathematics and using that as a guide for further direction (Davis, 1997). However, this deliberative attending may sometimes lead the listener to overlook or misinterpret what is being articulated.

Hermeneutic listening (Davis, 1997), on the other hand, is about negotiation, respectfulness, engagment and coevolution. It is messy and may appear unstructured but it can be a transformative experience (as in the case of Gerty from the Maoto and Wallace, 2006, study) if one is willing to interrogate the taken-for-granted assumptions that frame our perceptions and actions.

\section{Listening to understand}

Thomson and Thomson (1996) remark that 'how one teaches a subject is influenced greatly by the many ways one understands it' (p. 16). We expand on that: how one teaches should be influenced greatly by what one knows of the many ways the learners understand it. Henderson (1996) suggests that a teacher needs to be in touch with the different ways learners understand particular concepts:

I believe mathematics is a natural and deep part of human experience and that experiences of meaning in mathematics are accessible to everyone .... It is necessary to bring the power back to the meaning. (p. $x x)$

Henderson (1996) reminds us that a proof that is normally conceived is not the goal of mathematics, but just a means to an end. The goal is understanding, that is experiencing meaning in mathematics; without understanding one can never be satisfied. Henderson found in a course that he had taught for over 20 years that approximately $30 \%$ of his learners show him a meaning that he has never seen before, and which changes his own meaning. He argues that the different meanings people bring with them thus require different answers to the 'why' question. For example, when asked to construct a straight line, the different meanings held by different people require that different conditions be satisfied in order to justify whether a figure is a straight line. Henderson concludes that one can learn much about mathematics from those who have different meanings, who have different 'why' questions and who consequently require different proofs (p. xxiv).

In his study on a teacher's progression in learning to listen, Davis (1997) found that a teacher, Wendy, initially engaged mostly in evaluative listening. He noted one occasion when a potentially powerful learning opportunity was not picked up as Wendy apparently sought to stay the planned course (p. 360). However, when Wendy began to develop her own ideas about creating improved opportunities for learning for her learners, 'her modes of questioning and attending to student articulations ... changed dramatically' (Davis, 1997, p. 369). Davis describes her changed manner of listening as interpretative listening. As their researcher-teacher partnership evolved, there seemed to be a further change in Wendy's mode of attending to her learners' actions. This progression to hermeneutic listening was enabled by the 'presence of an interested colleague [Davis] who was willing to offer support and assistance and able to disrupt some of what was being taken-for-granted' (p. 371). He also attributes her transition to the fact that Wendy had time to think, having taken off a couple of months for maternity leave.

\section{Davis (1997) also argues that:}

the important distinguishing characteristic between conventional and constructivism-informed teaching is not to be found in the way the teacher speaks or structures her lesson (i.e., in the visible) but in the manner in which he or she listens (i.e., in the invisible). (p. 364)

The 'participatory, transformative competency of hermeneutic listening' enabled the teacher to enter as a participant into the learning of the classroom community. In the study, this learning to listen took time, deep reflection and the presence of a concerned colleague.

In their study, Peressini and Knuth (1998) describe how a teacher, George, struggled to accept a different solution 
method (to a task based on combinations) offered by a group of learners. Although he displayed flexibility and strove to listen to the learners and to make sense of what they were saying, it took the intervention of a pre-service teacher to convince George by explaining the group's solution process. These authors comment that the 'change in discourse was an "ah-ha" moment for George as he finally exclaimed that he "got it"' (Peressini \& Knuth, 1998, p. 120). Initially, George was puzzled by how the learners' 'wrong process' resulted in the same value that he obtained, but he struggled to see why this was so, until the intervention of the pre-service teacher. The student teacher helped George to see that the learners used a sample space consisting of sets with 10 elements amounting to a total of $\left(\begin{array}{c}876 \\ 10\end{array}\right)$ outcomes; this was different from his sample space of sets of 4 elements amounting to a total of $\left(\begin{array}{c}876 \\ 4\end{array}\right)$ outcomes, because they reasoned about the selection in a different manner. The learners' solution was $\frac{\left(\begin{array}{l}4 \\ 1\end{array}\right)\left(\begin{array}{c}872 \\ 9\end{array}\right)}{\left(\begin{array}{c}876 \\ 10\end{array}\right)}$, whilst George's solution was $\frac{\left(\begin{array}{c}10 \\ 1\end{array}\right)\left(\begin{array}{c}866 \\ 3\end{array}\right)}{\left(\begin{array}{c}876 \\ 4\end{array}\right)}$ (pp. 118-125). The differences in approach served to provide a meaningful example of the identity $\frac{\left(\begin{array}{c}m \\ 1\end{array}\right)\left(\begin{array}{c}n-m \\ k-1\end{array}\right)}{\left(\begin{array}{l}n \\ k\end{array}\right)}=\frac{\left(\begin{array}{c}k \\ 1\end{array}\right)\left(\begin{array}{c}n-k \\ m-1\end{array}\right)}{\left(\begin{array}{c}n \\ m\end{array}\right)}$ in the context of choosing winning tickets in a raffle (note that this generalisation is the authors' interpretation and does not appear in Peressini \& Knuth, 1998). In this case, George reached a different level of understanding of the use of combinations in the solution of the task as well as a different level of understanding of his learners when he was able to negotiate and permit a co-evolution of a shared meaning.

Thompson and Thompson (1994) examine the reflexive relations between the different 'ways of knowing' (p. 281) the ideas of speed and rate of a teacher, Bill, and a learner, Ann. In their study, they analyse the sources of the eventual dysfunctional communication and conclude that Bill had encapsulated his deep understanding of rate and proportionality within his language for numbers, operations and procedures; this undermined his effort to help Ann's understanding. Her conceptualisation of the situation was as a measurement task. This led to a language mismatch because, whilst the teacher spoke in terms of calculations, the learner was thinking of measurement; this led to a breakdown in communication and the learner was reduced to tears. Thomson and Thomson comment that Bill's:

\footnotetext{
language of arithmetic served him well as a personal representational system, or as a system for communicating with other competent quantitative reasoners ... Yet ... [it] served him poorly when trying to communicate with children ... who had not constructed the meanings and images that [he] had constructed. (p. 301)
}

The authors contend that sometimes 'nothing can be gained ... if the teachers' attention actually contributes to the child's difficulty' (Thomson \& Thomson, 1994, p. 301). This suggests that when teachers are unable to participate in the kind of hermeneutic listening that allows for negotiation, coevolution and shared meaning, the teachers' interventions can sometimes be more harmful than helpful, as was the situation in the case of Bill and Ann. The cases presented in this section illustrate that listening to learn is a challenging process because the teacher has to accept that the learners' different perspectives are legitimate and the teacher has to try to answer the 'why' question arising from the learners' different meaning of the situation. Often, mismatches that occur are never exposed because the learners' perspectives are not brought forward in a typical classroom.

\section{Listening to know: Another perspective of mathematical knowledge for teaching}

The discussion so far has revealed that, for a teacher, learning to listen can be a powerful learning tool for their own learning. Current discussions about mathematical knowledge for teaching sometimes tend to be silent on the contribution that can be made by learners in developing teachers' mathematical knowledge for teaching. The conception and definition of mathematical knowledge for teaching needs to be broadened to encompass the role learners can play in its development. How does mathematical knowledge for teaching change if we take the learner as the starting point? It may not significantly change the descriptions of the constructs encompassed by Ball et al. (2005), but it will change our understanding of the development and purpose of mathematical knowledge for teaching and how it is used in a Mathematics classroom that seeks to view learners as the starting point. The study by Maoto and Wallace (2006) showed that Gerty's engagement with her learners' understandings led to a deepening of her own mathematical knowledge for teaching.

Davis's (1997) study about Wendy showed that her participation in the learning of her learners was enabled by the development of her hermeneutic listening. This development was facilitated by time to reflect and by the presence of a supportive colleague. Peressini and Knuth's (1998) study on George revealed that his ability to listen and to understand his learners' alternative solution strategy was facilitated by the intervention of a student teacher. This acceptance of the different proof deepened his own understanding of the equivalence of the two approaches and strengthened his understanding of the ways in which combinations could be applied to such problems. Thompson and Thompson (1994) revealed that Bill's strong content knowledge did not help him to cross the divide between him and his learner. He was unable to understand the learner's different way of understanding the concept of speed, which resulted in an impasse.

These different cases demonstrate that the classroom can be a powerful site for the development of a teacher's mathematical knowledge. However, the development can only be enabled if the teacher is willing to grant the learner a voice and can engage in the kind of hermeneutic listening that allows participants to seek a shared meaning embedded in negotiation, respectfulness and co-evolution, despite the fact that this may be messy and appear unstructured. Furthermore, such learning is enhanced by the availability of interested colleagues who are willing to help the teacher disrupt the familiar ways of knowing and doing mathematics. 
Thus, by foregrounding the learners' role in the development of mathematical knowledge for teaching, our actual understanding of teaching mathematics for understanding is deepened and shifted.

\section{Concluding remarks}

In this article we argued that it is a democratic virtue to permit disagreement and contestation, for it is these processes that can lead to ending the occupation of our minds in education. The purpose of this article was to consider some of the implications of granting learners a voice and listening to them. In addition to helping learners experience democratic ways of handling dissent and disagreement, encouraging learners to participate more fully in classroom activities will also be a learning experience for the teacher.

Vithal's (1999) study was presented as an example of using project work as a vehicle for increasing the learners' participation in decision-making in their school. We noted that an important aspect of granting learners a voice is that they may not support the teacher's priorities. This disagreement may be seen as a valuable opportunity for teachers to learn more about their learners. It may be that their expectations are very different from the teacher's, and in some cases are even disapproving of the teacher's actions. Results from two studies support our contention that a teacher's role in listening to their learners is to build and not to break the learners' confidence.

We then turned our attention to the act of learning to listen, and how such a focus on listening could bring about meaningful change in the teacher's own learning. By presenting various cases from existing literature, this article showed that when teachers engage in hermeneutic listening, their own mathematical knowledge for teaching is deepened and strengthened. Bill was an example of a teacher who, because of his inability to listen hermeneutically, was unable to appreciate the different way of understanding held by his learner and consequently was unable to meet her learning needs. Thompson and Thompson (1994) comment that in such cases of mismatched instruction, the teachers' intervention may cause more harm.

Thus this article has argued that allowing learners an authentic voice can contribute to their experience of how democratic processes work when there are dissenting voices. Furthermore, by drawing on other research results, we have shown that a classroom in which the teacher is able to listen and which encourages learners to speak can be a crucial site for the development of mathematical knowledge of teachers. By learning how to listen in a respectful manner and as part of a negotiation and co-evolution of shared understanding, teachers can deepen and shift their understanding of mathematics, their understanding of learners and their understanding of their own learning.

Khuzwayo (1998) argues that redress in mathematics education in South Africa requires commitment to end the 'occupation of our minds'. This article has unpacked this process a little by focusing on the transformations that take place when learners' voices are taken seriously. When teachers provide their learners with the opportunity to have their voices heard, they initiate a disruption to the occupation of learners' minds by encouraging independent thought and discouraging passive acceptance of authority.

During this process of considering alternatives proposed by their learners, teachers deepen their own understanding of the procedures and concepts that they are teaching, as links and relationships between the concepts and procedures are interrogated. For example, we saw how Gerty had to go beyond her own understanding of an equal sign as denoting equivalence to acknowledge that her learner used it to represent the steps in the problem. She was able to see that her learner understood the factorisation procedure, when she was prepared to engage in hermeneutic listening to overcome the notational misconception. George experienced a leap in understanding of the concept of combinations when he forced himself to consider whether the learners' alternate modelling of a problem was correct, although different from his own model, thus seeking equivalence between two different representations of the situation. Henderson maintains that by seeking to understand the different meanings held by learners in his class, his own meaning of the concepts has changed. These learning experiences of the teachers recounted here did not take place in a lecture hall or from a textbook, but were a consequence of their attempts to understand their learners' ways of thinking. It was their learning to listen that facilitated deep shifts in their mathematical knowledge for teaching and provided examples of how teachers can also contribute to their own 'ending the occupation' of their minds.

\section{Acknowledgements Competing interests}

We declare that we have no institutional and/or personal or financial relationships which may have inappropriately influenced us in writing this article.

\section{Authors' contributions}

Both the authors, H.B.K. (University of Zululand) and S.B. (University of KwaZulu-Natal), worked together on this article, in discussing, drafting and refining the article.

\section{References}

Adler, J., \& Davis, Z. (2006). Opening another black box: Researching mathematics for teaching in mathematics education. Journal for Research in Mathematics Education, 37(4), 270-296.

Adler, J., Pournara, C., Taylor, D., Thorne, B., \& Moletsane, G. (2009). Mathematics and science teacher education in South Africa: A review of research, policy and practice in times of change. African Journal of Research in Mathematics, Science and Technology Education, Special Issue 2009, 28-46.

Ball, D.L., \& Bass, L. (2000). Interweaving content and pedagogy in teaching and learning to teach: Knowing and using mathematics. In J. Boaler (Ed.), Multiple perspectives on the teaching and learning of mathematics (pp. 83-104). Westport, CT: Ablex.

Ball, D.L., Hill, H.C., \& Rowan, B. (2005). Effects of teachers' mathematical knowledge for teaching on student achievement. American Educational Research Journal, 42(2), 371-406. http://dx.doi.org/10.3102/00028312042002371 
Ball, D.L., Thames, M.H., \& Phelps, G. (2008). Content knowledge for teaching. What makes it special? Journal of Teacher Education, 59(5), 389-407. http://dx.doi. org/10.1177/0022487108324554

Bansilal, S., James, A., \& Naidoo, M. (2010). Whose voice matters? LEARNERS South African Journal of Education, 30(1), 153-165. Available from http://www. sajournalofeducation.co.za/index.php/saje/article/view/236/177

Clarke, D.J. (2002). International perspectives on mathematics classrooms. In C. Malcolm, \& C. Lubisi (Eds.), Proceedings of the 10th Annual Conference of the Southern African Association for Research in Mathematics, Science and Technology Education (pp. 7-9). Durban: University of Natal. http://dx.doi. Technology Education $(\mathrm{pp}$.
org/10.1007/0-306-47228-7

Conference Board of the Mathematical Sciences. (2001). The mathematical education of teachers. Washington, DC: American Mathematical Society and Mathematica Association of America. Available from http://cbmsweb.org/MET Document/

Davis, B. (1997). Listening for differences: An evolving conception of mathematics teaching. Journal for Research in Mathematics Education, 28(3), 355-376. http:// dx.doi.org/10.2307/749785

Fasheh, M. (1996). The main challenge: Ending the occupation of our minds. The main means: Building learning environments and re-contextual knowledge. In T. Kjaergard, A. Kvamme, \& N. Linden (Eds.), Proceedings of the Third International Conference on Political Dimensions of Mathematics Education (pp. 13-26). Bergen, Norway: Caspar Forlag.

Guttman, A. (1987). Democratic education. Princeton, NJ: Princeton University Press.

Henderson, D.W. (1996). Experiencing geometry on a plane and a sphere. Upper Saddle River, NJ: Prentice-Hall.

Khuzwayo, H.B. (1998). 'Occupation of our minds.' A dominant feature in mathematics education in South Africa. In P. Gates (Ed.), Proceedings of the First International Mathematics Education and Society Conference (pp. 219-231). Nottingham: Centre for the Study of Mathematics Education. Available from http://www. nottingham.ac.uk/csme/meas/papers/khuzwayo.html
Maoto, S., \& Wallace, J. (2006). What does it mean to teach mathematics for understanding? When to tell and when to listen. African Journal of Research in Mathematics, Science and Technology Education, 10(1), 59-70.

Moodley, M. (2008). Investigating the experiences and perceptions that learners face in the mathematics classroom. Unpublished master's thesis. University of KwaZulu-Natal, Durban, South Africa.

Naidoo, M. (2007). Learners' voices on assessment feedback: Case studies based at a KwaZulu-Natal school. Unpublished master's thesis. University of KwaZulu-Natal, Durban, South Africa.

Peressini, D., Borko, H., Romagnano, L., Knuth, E., \& Willis, C. (2004). A conceptual framework for learning to teach secondary mathematics: A situative perspective. Educational Studies in Mathematics, 56(1), 67-96. http://dx.doi.org/10.1023/ B:EDUC.0000028398.80108.87

Peressini, D.D., \& Knuth, E.J. (1998). Why are you talking when you could be listening? The role of discourse and reflection in the professional development of a
secondary mathematics teacher. Teaching and Teacher Education, 14(1), 107-125. http://dx.doi.org/10.1016/S0742-051X(97)00064-4

Skovsmose, O. (2004, July). Globalisation, ghettoising and uncertainty: Challenges for critical mathematics education. Paper presented at the 10th International Congress on Mathematical Education, Copenhagen, Denmark.

Thompson, P.W., \& Thompson, A.G. (1994). Talking about rates conceptually, Part I: A teacher's struggle. Journal for Research in Mathematics Education, 25(3), 279-303. http://dx.doi.org/10.2307/749339

Thompson, P.W., \& Thompson, A.G. (1996). Talking about rates conceptually, Part II: A mathematical knowledge for teaching. Journal for Research in Mathematics Education, 27(1), 2-24. http://dx.doi.org/10.2307/749194

Vithal, R. (1999). Democracy and authority: A complementarity in mathematics education? ZDM: The International Journal on Mathematics Education, 31(1), 27-36. http://dx.doi.org/10.1007/s11858-999-0005-y

Young, P. (2000). I might as well give up. Journal of Further Higher Education, 24(3), 409-418. http://dx.doi.org/10.1080/030987700750022325 